\title{
Factor Affecting Microwave Assisted Preparation of Activated Carbon from Local Raw Materials
}

\author{
M. A. Elsayed*, O. A. Zalat \\ Egyptian Armed Forces, Cairo, Egypt \\ *E-mail address: aboelfotoh@gmail.com
}

\begin{abstract}
This study illustrates the preparation of activated carbon (AC) from Corn Cob (CC) via microwave assisted $\mathrm{K}_{2} \mathrm{CO}_{3}$ activation. The effect of operational parameters including chemical impregnation ratio (0.25-1.25), microwave power $(90-800 \mathrm{~W})$ and irradiation time $(1-9 \mathrm{~min})$ on the carbon yield and adsorption capability of derived Corn Cob Activated Carbon (CCAC) were investigated. The results indicated that the optimum conditions were as follows: microwave power of $600 \mathrm{~W}$, microwave radiation time of $5 \mathrm{~min}$ and the impregnation ratio of $\mathrm{K}_{2} \mathrm{CO}_{3}$ was $0.75 \mathrm{~g} / \mathrm{g}$. The optimum conditions resulted in CCAC with a maximum adsorption capacity of $275.32 \mathrm{mg} / \mathrm{g}$ for MB and carbon yield of $27.09 \%$. The BET surface area, Langmuir surface area and total pore volume were determined to be $765 \mathrm{~m}^{2} / \mathrm{g}, 834 \mathrm{~m}^{2} / \mathrm{g}$ and $0.43 \mathrm{~cm}^{3} / \mathrm{g}$, respectively.
\end{abstract}

Keywords: Activated carbon; Chemical Activation; Adsorption; Methylene blue; Microwave Corn $\mathrm{Cob}$

\section{INTRODUCTION}

The removal of toxic dyes from dilute or concentrated solutions has received a great deal of attention in the last few decades. In recent years, stringent statutory regulations have been introduced to reduce the discharge of dyes to low level at source, particularly from textile, paper, cosmetics and food processing industries. The discharge of effluents from these industries contain large amount of dyes which is toxic to aquatic life [1] .

This has been partially achieved by minimization and recycling of existing resources. With the increasing demand for cleaner water, attention has been focused on improvements to existing treatments and the development of new techniques and materials $[2,3]$.

The discharge of dyes into natural water impedes light penetration and destroy the biological processes [4]. In addition, many dyes are toxic to some organisms causing direct destruction of aquatic communities. Some dyes can cause allergic dermatitis, skin irritation, cancer and mutation in man [5]. Wastewaters from dyeing industries released into nearby land or rivers without any treatment because the conventional treatment methods are not cost effective in the Egypt context.

As dyes are designed to resist breakdown with time, exposure to sunlight, water, soap and oxidizing agent, cannot be easily removed by conventional wastewater treatment processes due to their complex structure and synthetic origins [2, 6, 7]. Adsorption techniques to remove dyes from water have been widely used. It has been found to be an economical and effective treatment method for removal of dyes due to its sludge free clean operation [2]. 
Adsorption is one of the most effective methods and activated carbon is the preferred adsorbent widely employed to treat wastewater containing different classes of dyes, recognizing the economic drawback of commercial activated carbon $[4,8]$.

Many investigators have studied the feasibility of using inexpensive alternative materials like pearl millet husk, date pits, saw dust, buffing dust of leather industry, coir pith, crude oil residue, tropical grass, olive stone, almond shells, pine bark, wool waste, coconut shell etc., as carbonaceous precursors for the removal of dyes from water and wastewater [3, 5, 9-11].

In present work, activated carbon was prepared from Corn Cob by microwave assisted $\mathrm{K}_{2} \mathrm{CO}_{3}$ activation. Corn $\mathrm{Cob}$ was chosen as a natural and a promising alternative due to its abundance and its low cost commercial value. Effects of the radiation time, impregnation ratio of $\mathrm{K}_{2} \mathrm{CO}_{3}$ to Corn $\mathrm{Cob}$, radiation power on the adsorption capacity and yield of the activated carbon were researched to determine the optimum preparation conditions.

\section{EXPERIMENTAL WORK}

\section{a. Materials and methods}

Corn Cob (CC), an agricultural waste, was the precursor used in the present study. The raw precursor was washed exhaustively with distilled water to remove adhering dirt from the surface. Dried CC was cut, crushed, and screened to a particle size of 1-2 $\mathrm{mm}$. The carbonization process was carried out by loading $100 \mathrm{~g}$ of dried precursor into a modified muffle furnace, under $\mathrm{N}_{2}$ gas flow $\left(150 \mathrm{~cm}^{3} / \mathrm{min}\right)$ and heated up to a carbonization temperature of $700 \circ \mathrm{C}$, at the heating rate of $10 \circ \mathrm{C} / \mathrm{min}$. The char produced was mixed with $\mathrm{K}_{2} \mathrm{CO}_{3}$ pellets with different impregnation ratio (IR), defined as:

$$
\operatorname{IR}=\frac{\mathrm{w}_{\mathrm{K}_{2} \mathrm{CO}_{3}}}{\mathrm{w}_{\mathrm{Char}}}
$$

where $W_{K_{2} \mathrm{CO}_{3}}$ and $W_{\text {Char }}$ are the dry weight of $\mathrm{K}_{2} \mathrm{CO}_{3}$ pellets $(\mathrm{g})$ and Corn $\mathrm{Cob}(\mathrm{CC})(\mathrm{g})$.

A modified microwave oven with continuous output power and a frequency of 2.45 $\mathrm{GHz}$ was applied for the activation step. Nitrogen flow was used to purge air in the reactor before microwave heating and it continued to flow during the cooling stage. The oven has a power controller to select different power levels from 1 to 5 which is corresponding to 90, $180,360,600$ and $800 \mathrm{~W}$ and a timer for various exposure times at a set microwave power level. The activated samples were washed sequentially with deionized water and $0.1 \mathrm{M}$ hydrochloric acid until the $\mathrm{pH}$ of the washing solution reached 6-7. The yield was calculated as the ratio of the dry weight of resultant activated carbon to the weight of the raw precursor.

\section{b. Methylene Blue adsorption equilibrium experiments}

The batch adsorption experiments were undertaken in a set of $250 \mathrm{~mL}$ Erlenmeyer flasks containing $0.20 \mathrm{~g}$ of adsorbent and $200 \mathrm{ml}$ of dye solutions within the initial concentration range

of $50-500 \mathrm{mg} / \mathrm{L}$. The mixture was agitated at $120 \mathrm{rpm}$ and $25{ }^{\circ} \mathrm{C}$ until the equilibrium was reached. The concentration of methylene blue (MB) dye solution was determined using Agilant UV-Vis Cary 60 PC scan double beam recording spectrophotometer using (1) cm glass cells at $668 \mathrm{~nm}$.

The amount of adsorption at time $t, Q_{t}(\mathrm{mg} / \mathrm{g})$ was calculated using the following formula 


$$
Q_{t}=\frac{c_{0}-c_{t}}{W} V
$$

where $C_{t}(\mathrm{mg} / \mathrm{L})$ is the liquid concentration of dye at any time, $\mathrm{C}_{0}(\mathrm{mg} / \mathrm{L})$ is the initial concentration of the dye in solution. $\mathrm{V}$ is the volume of the solution (L) and $\mathrm{W}$ is the mass of dye adsorbent $(\mathrm{g})$. The amount of equilibrium adsorption $\mathrm{Q}_{\mathrm{e}}(\mathrm{mg} / \mathrm{g})$ was calculated using the formula.

$$
Q_{\theta}=\frac{c_{0}-c_{\varepsilon}}{W} V
$$

where $\mathrm{C}_{0}$ and $\mathrm{C}_{\mathrm{e}}(\mathrm{mg} / \mathrm{L})$ are the liquid concentrations of dye initially and at equilibrium.

\section{c. Characterization of Corn Cob activated carbon (CCAC)}

The specific surface areas of AC produced by the optimum conditions as well as the carbonized char were determined by the BET method using nitrogen as the adsorbate at $77 \mathrm{~K}$ utilizing the commonly used Autosorb instrument. Prior to the measurements, the samples were out gassed at $300^{\circ} \mathrm{C}$ under nitrogen for at least $12 \mathrm{~h}$. Nitrogen adsorption isotherms of $\mathrm{AC}$ and char were tested over a relative pressure $\left(\mathrm{P} / \mathrm{P}_{0}\right)$ range from $10^{-7}$ to 1 . The total pore volumes were estimated to be the equivalent liquid volume of the adsorbate $\left(\mathrm{N}_{2}\right)$ at a relative pressure of 0.99. The BET surface of the samples was calculated by the Brunauer-EmmettTeller (BET) equation.

Chemical characterization of functional groups was detected by Fourier transform infrared spectrometer (FTIR-100, Perkin Elmer) in the scanning range of $4000-400 \mathrm{~cm}^{-1}$. The adsorbent and potassium bromide $(\mathrm{KBr})$ were dried in an oven and then ground together in a ratio of 20:1 (KBr:AC) for FTIR measurement using disc sample method.

\section{RESULTS AND DISCUSSION}

\subsection{Preparation of CCAC}

\subsubsection{Effect of chemical impregnation ratio}

Effect of chemical impregnation ratio (IR) on the carbon yield and adsorption uptake of $\mathrm{MB}$ was evaluated at the microwave power of $360 \mathrm{~W}$ and irradiation time of $5 \mathrm{~min}$. It was found from Fig. 1 that increasing IR from 0.25 to 0.75 showed an enhancement of carbon yield from 25.12 to $40.34 \%$. Beyond the value, further increase in IR leads to a gradual decrease of carbon yield. Similarly, increasing IR from 0.25 to 0.75 indicated an increase of adsorption uptake from 120.31 to $250.79 \mathrm{mg} / \mathrm{g}$, and then steadily decreased. The best adsorption uptake and carbon yield of CCAC were obtained at the $\mathrm{K}_{2} \mathrm{CO}_{3} /$ char ratio of 0.75 . The development of porosity by $\mathrm{K}_{2} \mathrm{CO}_{3}$ activation was associated with gasification reaction with the formation of potassium, potassium carbonate and hydrogen [11]. When IR was lower than 0.75 , the carbons on the active sites reacted partially lowering the adsorption uptake and carbon yield. As IR increased, it was assumed that metallic potassium formed during the gasification process would diffuse into the interior of char matrix contributing to the development of new porosities. Correspondingly, the adsorption uptake was further enhanced [12]. When the ratio had reached to its optimum value, the active sites on the carbons had 
reacted completely and the adsorption uptake had reached its maximum amount. Beyond the optimum value, the catalytic oxidation entailed the widening of mesoporous structures and carbon burn off [12].

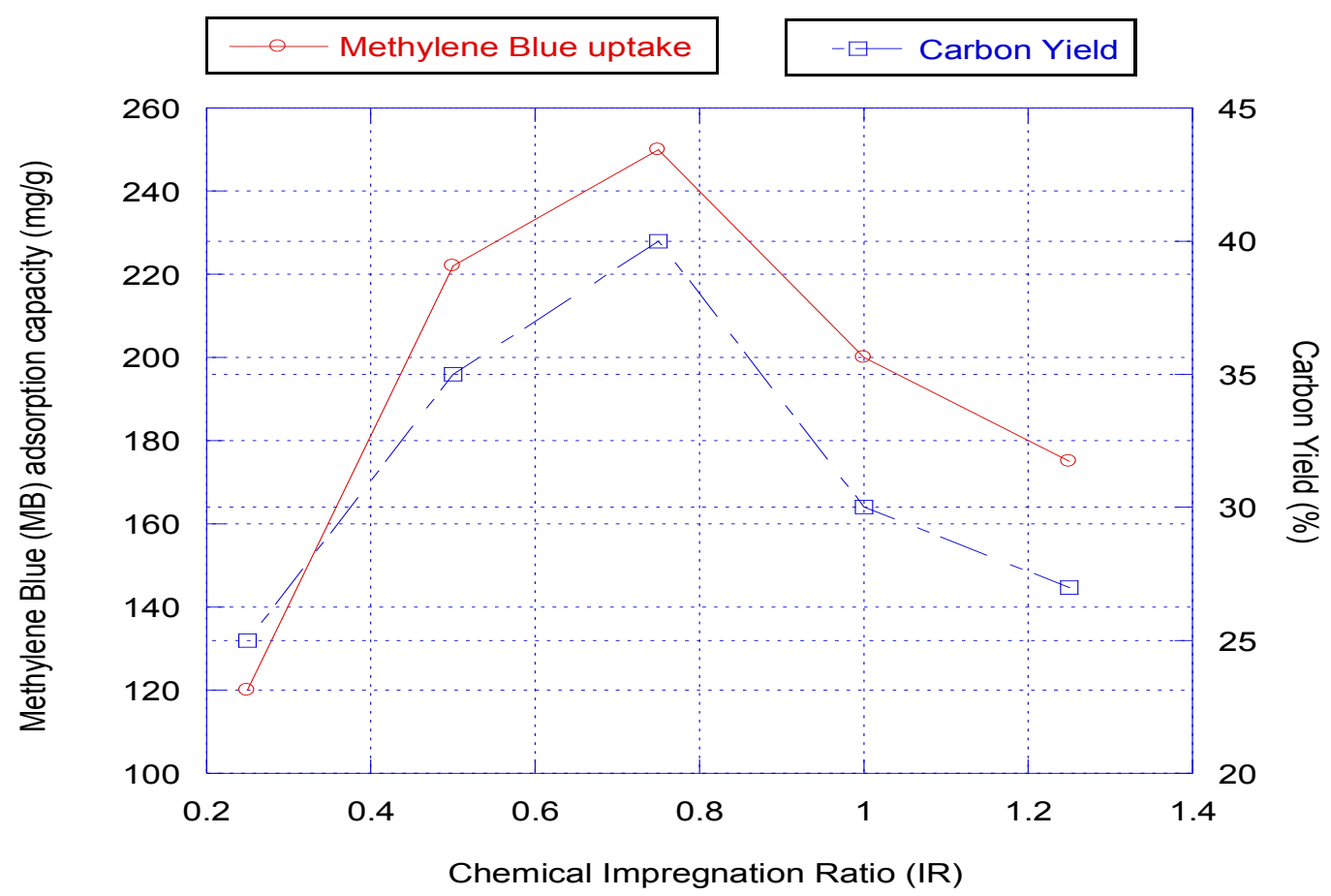

Figure 1. Effects of chemical impregnation ratio on the carbon yield and MB adsorption uptake. (preparation conditions: microwave power $=360 \mathrm{~W}$; radiation time $=5 \mathrm{~min}$ ).

Identical results were observed by Foo and Hameed from the $\mathrm{KOH}$ activation of fruit residue (biodiesel industry solid residue). Their results showed that the diffusion of metallic potassium formed during the gasification process widens the exit pores and creates new pores. The adsorption capacity, therefore, increased from 132.74 to $253.44 \mathrm{mg} / \mathrm{g}$ by augmenting the impregnation ratio from 0.25 to 1.00 (wt\%) at a microwave power level of $600 \mathrm{~W}$ and an activation time of $7 \mathrm{~min}$. At the optimum impregnation ratio, the carbons on the active sites reacted completely with the $\mathrm{KOH}$ and the adsorption capacity was maximized [13].

\subsubsection{Effect of microwave power}

Effect of microwave power on the adsorption uptake and carbon yield was investigated at the IR of 0.75 and irradiation time of $5 \mathrm{~min}$. Fig. 2. Under low microwave power of 90 and $180 \mathrm{~W}$, the pore structure was not adequately developed, and the adsorption uptake is slightly increased however the carbon yield is decreased, indicating no continual reaction between the char and activating agent. At higher microwave power of 360 and $600 \mathrm{~W}$, the adsorption uptake was drastically increased, mainly attributed to the combined effect of internal and volumetric heating widening the existing pores. Meanwhile, the loss rate of carbon increased proportional to the microwave power level, possibly due to the fierce reaction at higher thermal radiation which resulted in greater weight loss of the carbon sample. At high radiation power of $800 \mathrm{~W}$, over gasification might occur with detrimental impact of reducing surface area and porosity, thus the adsorption uptake and carbon yield were progressively decreased. 


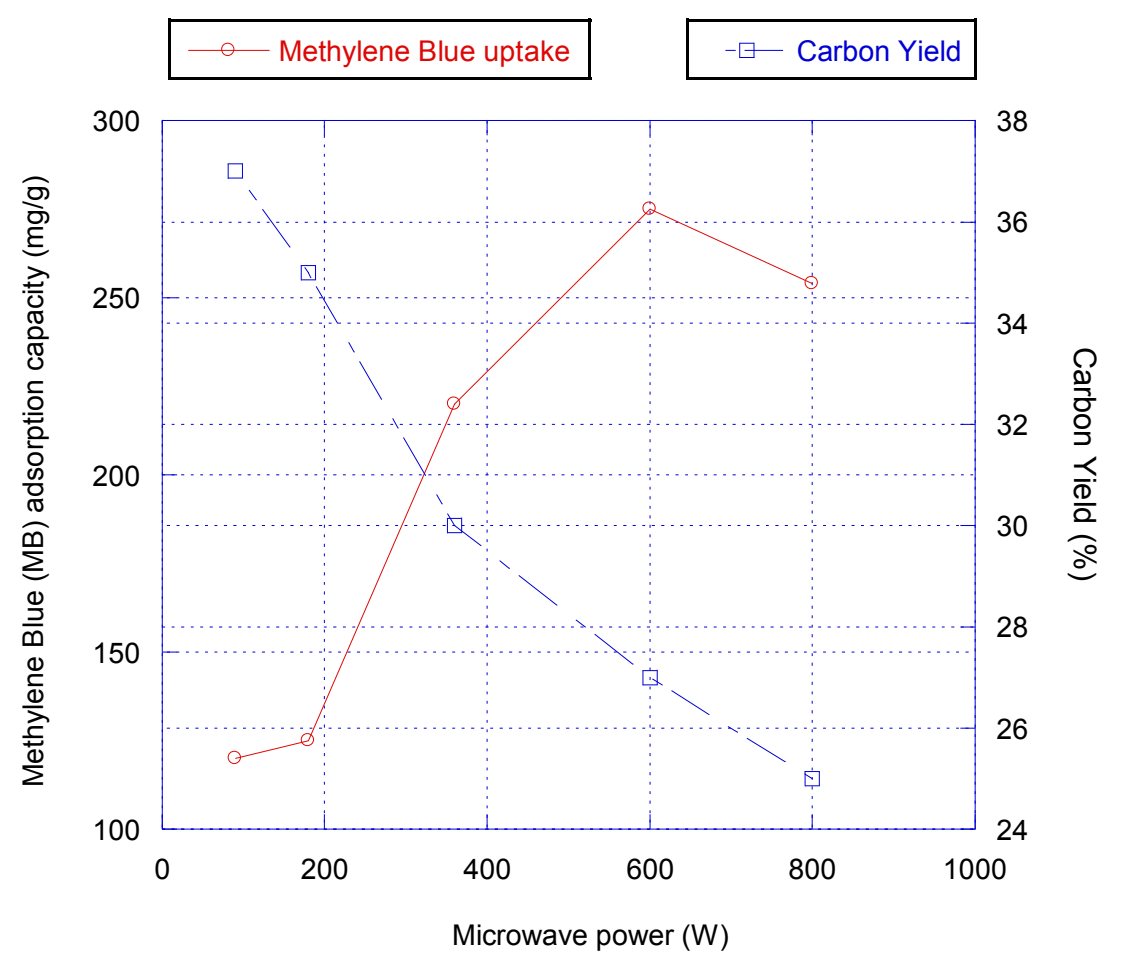

Figure 2. Effects of microwave power on the carbon yield and adsorption uptake (preparation conditions: chemical impregnation ratio $=0.75$; radiation time $=5 \mathrm{~min}$ ).

\subsubsection{Effect of radiation time}

Microwave radiation time is another decisive factor affecting the adsorption uptake and carbon yield. Effect of radiation time was conducted at the IR of 0.75 and microwave input power of $600 \mathrm{~W}$ (Fig. 3). Generally, prolonging radiation time from 1 to 5 min exhibited an enhancement of adsorption uptake from $175.99 \mathrm{mg} / \mathrm{g}$ to $265.05 \mathrm{mg} / \mathrm{g}$, and beyond the limit, the adsorption uptake was slightly decreased. Meanwhile, the loss rate of carbon was found increased proportional to the radiation time. The result implied that prolonging radiation time promoted an acceleration of energy, which in turn increased the reaction rates, thus developed the internal porosity of the CCAC. The best conditions were inferred at the IR of 0.75 , microwave power of $600 \mathrm{~W}$ and irradiation of $6 \mathrm{~min}$. Beyond this condition, further heat treatment might produce local hotspots, which considerably destroyed the pore walls between the adjacent pores. This work resulted in higher adsorption uptake as compared previous studies [10]. 


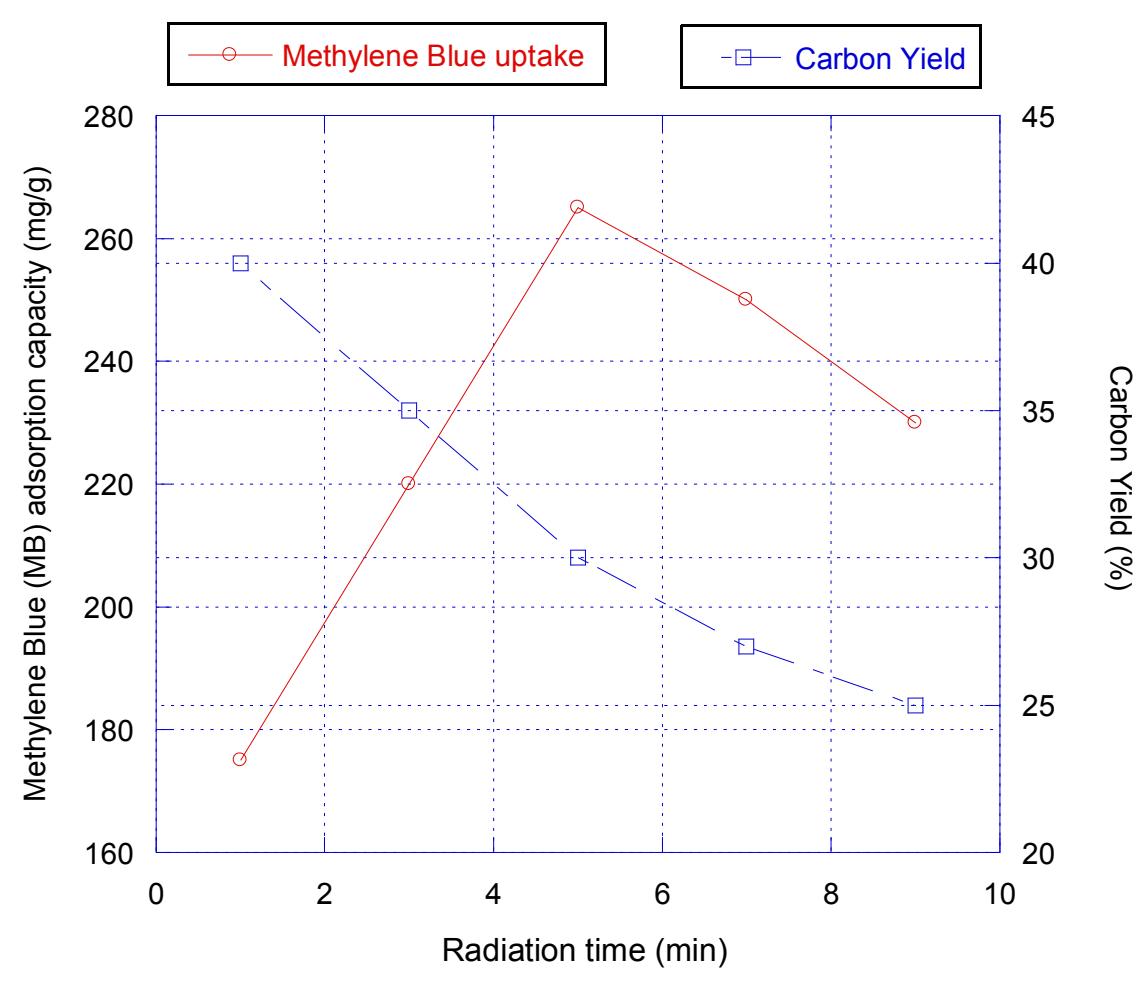

Figure 3. Effects of radiation time on the carbon yield and adsorption uptake (preparation conditions: chemical impregnation ratio $=0.75$; microwave power $=600 \mathrm{~W})$.

Guo and Lua [14] used a different microwave power level and activation time to investigate the effects of these variables on the properties of AC. At low microwave power levels of 80,150 and $300 \mathrm{~W}$ with an exposure time of $60 \mathrm{~min}$, the microwave radiation has no effect on the density and total porosity of the prepared AC. No reaction occurs between the char and the agent at the lower power levels, but at the high microwave power levels of 450 and $750 \mathrm{~W}$, the total pore volume increased progressively with increasing microwave radiation time. They attained an increase of $20.9 \%$ in the total porosity of the AC by increasing the exposure time from $5 \mathrm{~min}$ to $1 \mathrm{~h}$ at the microwave power level of $750 \mathrm{~W}$. The pores created during carbonization would, therefore, be enlarged by a combination of the effects of continual carbonization and the carbon- $\mathrm{CO}_{2}$ reaction. New pores will be created and formed by increasing the reaction time.

\subsection{Textural and surface characterization of CCAC}

Detailed characteristics of the porosities of CCAC and that of carbonized char were summarized in Table 1. The total pore volume was estimated by converting the amount of $\mathrm{N}_{2}$ gas adsorbed at a relative pressure of 0.95 to equivalent liquid volume of the adsorbate $\left(\mathrm{N}_{2}\right)$. The mesopore volume was determined by subtracting micropore volume from the total pore volume. From Table 1, it was evident that the micrpores of CCAC account about $72 \%$ of the total pore volume, with a well developed porous structure. The micropore volume, external surface area and micropore surface area that deduced from the t-method were tabulated in the same table. In the present study, it can be found that the BET surface area, Langmuir surface 
area, and total pore volume of CCAC were greatly improved compared to char, implying development of additional pores during the microwave irradiation stage [15-17].

Table 1. Porosity structures of CCAC and carbonized char.

\begin{tabular}{ccc}
\hline Properties & CCAC & Carbonized char \\
\hline BET surface area $\left(\mathrm{m}^{2} / \mathrm{g}\right)$ & 765 & 507 \\
Micropore surface area $\left(\mathrm{m}^{2} / \mathrm{g}\right)$ & 682 & 436 \\
External surface area $\left(\mathrm{m}^{2} / \mathrm{g}\right)$ & 534 & 380 \\
Langmuir surface area $\left(\mathrm{m}^{2} / \mathrm{g}\right)$ & 834 & 567 \\
Total pore volume $\left(\mathrm{cm}^{3} / \mathrm{g}\right)$ & 0.43 & 0.32 \\
Micropore volume $\left(\mathrm{cm}^{3} / \mathrm{g}\right)$ & 0.31 & 0.26 \\
Mesopore volume $\left(\mathrm{cm}^{3} / \mathrm{g}\right)$ & 0.12 & 0.06 \\
Average pore size $(\AA)$ & 25.3 & 22.1 \\
\hline
\end{tabular}

The FT-IR spectra of the carbonized chare and CCAC were shown in Fig. 4. It is seen that the absorbance bands were observed to have peaks at 3441.6, 2352.5, 2336.6, 1627.7, $1604.0,1346.6,1120.8,1053.3 \mathrm{~cm}^{-1}$. Most of these bands have been reported by other investigators for different carbon materials. The band at around $3441.6 \mathrm{~cm}^{-1}$ can be assigned to the ${ }^{-} \mathrm{OH}$ stretching vibration mode of hydroxyl functional groups[9]. The bands located at about 2352.6 and $2336.6 \mathrm{~cm}^{-1}$ are attributed to the $\mathrm{C} \equiv \mathrm{C}$ stretching [18]. The peak at 1627.7 $\mathrm{cm}^{-1}$ and $1604.0 \mathrm{~cm}^{-1}$ were the characteristics of the $\mathrm{C}-\mathrm{O}$ stretching vibration of lactonic and carbonyl groups[14]. The peaks occurring at 1346.5, 1120.8 and $1053.3 \mathrm{~cm}-1$ are all ascribed to oxygen functionalities such as highly conjugated $\mathrm{C}-\mathrm{O}$ stretching, $\mathrm{C}-\mathrm{O}$ stretching in carboxylic groups, and carboxylate moieties[17].

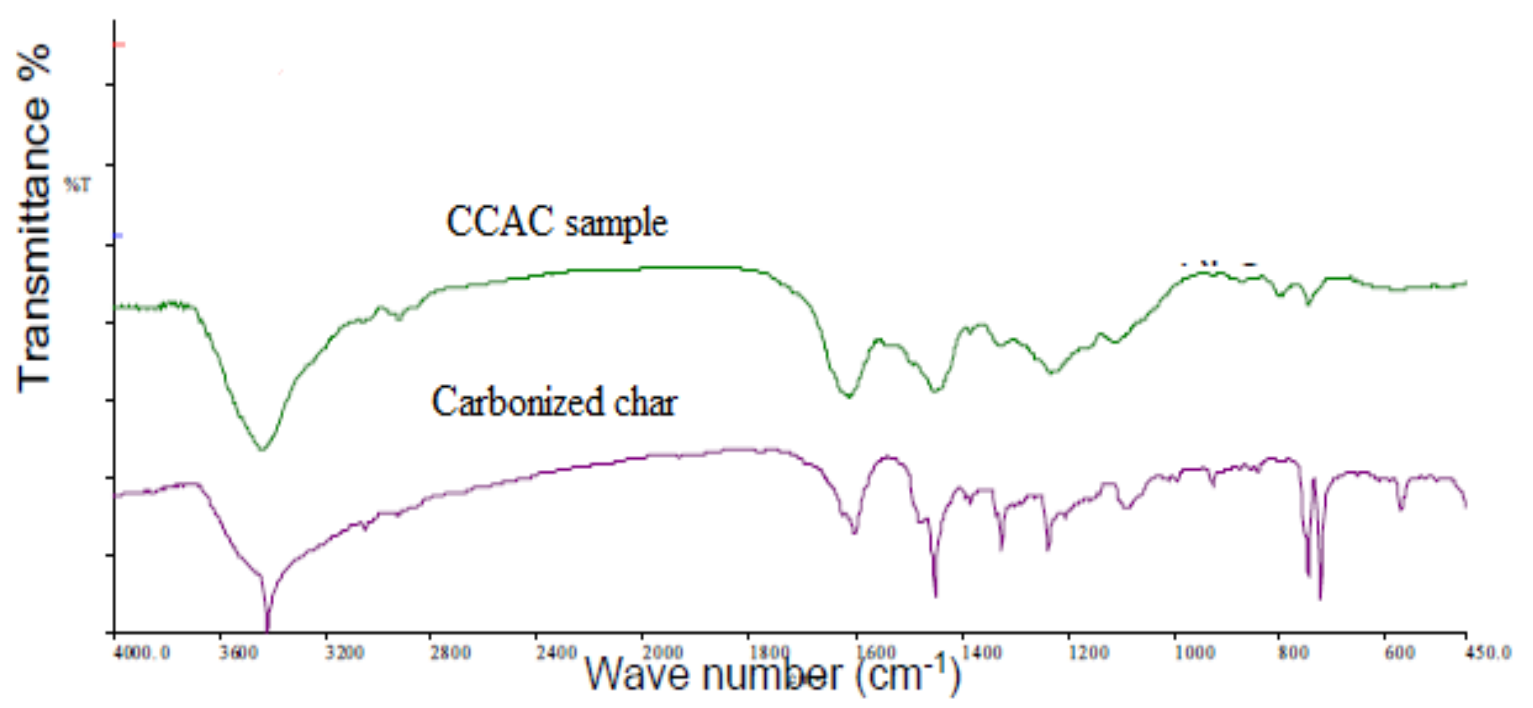

Figure 4. FTIR spectrum of the Corn Cob Activated Carbon (CCAC) and the carbonized char. 


\section{CONCLUSION}

Activated carbons with well-developed microporosity and high surface areas can be manufactured from agricultural waste (corn cob) using microwave assisted chemical activation by $\mathrm{K}_{2} \mathrm{CO}_{3}$. Experimental results showed that microwave heating could shorten the processing period, and remarkably, produce a high-quality activated carbon. CCAC prepared by microwave assisted $\mathrm{K}_{2} \mathrm{CO}_{3}$ activation attained maximum BET surface area as $765.75 \mathrm{~m}^{2} / \mathrm{g}$, total pore volume as $0.43 \mathrm{~cm}^{3} / \mathrm{g}$ and a high contribution of micropores as $72 \%$ at IR of 0.75 , microwave power of $600 \mathrm{~W}$ and irradiation time of $5 \mathrm{~min}$. These best conditions resulted in activated carbon with a maximum adsorption capacity of $275.32 \mathrm{mg} / \mathrm{g}$ for $\mathrm{MB}$ and carbon yield of $27.09 \%$, respectively.

\section{References}

[1] K. Lavelle, "Handbook of water and wastewater treatment technology," Applied Catalysis B: Environmental, vol. 6, pp. N8-N9, 1995.

[2] T. Robinson, B. Chandran, and P. Nigam, "Removal of dyes from a synthetic textile dye effluent by biosorption on apple pomace and wheat straw," Water research, vol. 36, pp. 2824-2830, 2002.

[3] D. Mohan, K. P. Singh, G. Singh, and K. Kumar, "Removal of dyes from wastewater using flyash, a low-cost adsorbent," Industrial \& engineering chemistry research, vol. 41, pp. 3688-3695, 2002.

[4] C. Y. Shiau and C. C. Pan, "Adsorption of basic dyes from aqueous solution by various adsorbents," Separation science and technology, vol. 39, pp. 1733-1750, 2005.

[5] G. Crini, "Non-conventional low-cost adsorbents for dye removal: a review," Bioresource technology, vol. 97, pp. 1061-1085, 2006.

[6] L. Wang, J. Zhang, and A. Wang, "Removal of methylene blue from aqueous solution using chitosan- $<\mathrm{i}>\mathrm{g}</ \mathrm{i}>$-poly (acrylic acid)/montmorillonite superadsorbent nanocomposite," Colloids and Surfaces A: Physicochemical and Engineering Aspects, vol. 322, pp. 47-53, 2008.

[7] C. Namasivayam and D. Kavitha, "Removal of Congo Red from water by adsorption onto activated carbon prepared from coir pith, an agricultural solid waste," Dyes and pigments, vol. 54, pp. 47-58, 2002.

[8] J. S. Mattson and H. B. Mark, Activated carbon: surface chemistry and adsorption from solution: M. Dekker New York, 1971.

[9] S. Babel and T. A. Kurniawan, "Low-cost adsorbents for heavy metals uptake from contaminated water: a review," Journal of hazardous materials, vol. 97, pp. 219-243, 2003.

[10] V. Gupta, "Application of low-cost adsorbents for dye removal-A review," Journal of environmental management, vol. 90, pp. 2313-2342, 2009.

[11] V. Gupta, I. Ali, and D. Mohan, "Equilibrium uptake and sorption dynamics for the removal of a basic dye (basic red) using low-cost adsorbents," Journal of Colloid and Interface Science, vol. 265, pp. 257-264, 2003. 
[12] K. Foo and B. Hameed, "Textural porosity, surface chemistry and adsorptive properties of durian shell derived activated carbon prepared by microwave assisted $\mathrm{NaOH}$ activation," Chemical Engineering Journal, vol. 187, pp. 53-62, 2012.

[13] K. Foo and B. Hameed, "Microwave-assisted preparation and adsorption performance of activated carbon from biodiesel industry solid reside: influence of operational parameters," Bioresource technology, vol. 103, pp. 398-404, 2012.

[14] J. Guo and A. C. Lua, "Preparation of activated carbons from oil-palm-stone chars by microwave-induced carbon dioxide activation," Carbon, vol. 38, pp. 1985-1993, 2000.

[15] T. Wigmans, "Industrial aspects of production and use of activated carbons," Carbon, vol. 27, pp. 13-22, 1989.

[16] W. Li, L.-b. Zhang, J.-h. Peng, N. Li, and X.-y. Zhu, "Preparation of high surface area activated carbons from tobacco stems with $\mathrm{K}<\mathrm{sub}>2</$ sub $>\mathrm{CO}<\mathrm{sub}>3</$ sub $>$ activation using microwave radiation," Industrial crops and products, vol. 27, pp. 341347, 2008.

[17] S. Sircar, T. Golden, and M. Rao, "Activated carbon for gas separation and storage," Carbon, vol. 34, pp. 1-12, 1996.

[18] K. Yang, J. Peng, C. Srinivasakannan, L. Zhang, H. Xia, and X. Duan, "Preparation of high surface area activated carbon from coconut shells using microwave heating," Bioresource technology, vol. 101, pp. 6163-6169, 2010. 